\title{
O fenômeno corpo/corporeidade na compreensão de concluintes de licenciatura em Educação Física
}

\author{
The body/corporeality phenomenon in the understanding of undergraduate students in Physical Education \\ Weisiana Santana de Castro Paiva \\ Universidade Federal do Triângulo Mineiro (UFTM), Brasil \\ Wagner Wey Moreira \\ Universidade Federal do Triângulo Mineiro (UFTM), Brasil \\ weymoreira@uol.com.br
}

\begin{abstract}
Resumen:
Este artículo tuvo por objetivo analizar el discurso acerca de la comprensión del fenómeno cuerpo/corporeidad de alumnos concluyentes de licenciatura en Educación Física. Esta investigación cualitativa, de carácter descriptivo, fue realizada en campi universitarios en la región del Triângulo Mineiro, Minas Gerais, que ofrecían dos licenciaturas en Educación Física. El instrumento utilizado fue la entrevista con cuestiones abiertas. El análisis de contenido: técnica de elaboración y análisis de unidades de significado ha sido utilizada para la construcción de los resultados. Participaron 41 alumnos concluyentes (13 mujeres y 28 hombres) de cursos de Licenciatura en Educación Física. Las respuestas obtenidas confirmaron una visión de cuerpo vinculada a la parte biológica, ignorando que somos seres corpóreos y que el cuerpo debe ser comprendido como un todo, al contrario de una máquina. Tal aserción nos lleva a confirmar la concepción dualista de cuerpo/mente, presentada en los puntos de convergencia y/ o de divergencia establecidos por los objetivos de esta investigación.
\end{abstract}

Palabras Clave: Cuerpo, Corporeidad, Alumnos concluyentes, Licenciatura en Educación Física.

\section{Resumo:}

Este artigo teve por objetivo analisar o discurso sobre o entendimento do fenômeno corpo/corporeidade de alunos concluintes de licenciatura em Educação Física. Pesquisa qualitativa, de cunho descritivo, foi realizada em campi universitários na região do Triângulo Mineiro, Minas Gerais, junto a duas licenciaturas em Educação Física. O instrumento de pesquisa foi a entrevista com questões abertas. A Análise de Conteúdo: técnica de elaboração e análise de unidades de significado foi a empregada para a construção dos resultados. Participaram 41 concluintes (13 mulheres e 28 homens) de cursos de Licenciatura em Educação Física. As respostas obtidas confirmaram uma visão de corpo voltada para a parte biológica, ignorando que somos seres corpóreos e que o corpo deve ser trabalhado como um todo, ao contrário de uma máquina. Tal asserção nos leva a confirmar a concepção dualista de corpo/mente, apresentada nos pontos de convergência e/ou de divergência estabelecidos pelos objetivos do estudo.

PalaVras-chaVe: Corpo, Corporeidade, Alunos concluintes, Licenciatura em Educação Física.

\section{INTRODUÇão}

No ano 2018, surgiu o interesse de realizar uma pesquisa sobre corpo/corporeidade com o propósito de saber como os concluintes dos cursos de Graduação em Educação Física, na trilha das Licenciaturas, compreendem o significado de corpo/corporeidade.

Consideramos, de forma plena, que precisamos estar sempre em busca de novos métodos, procedimentos e didáticas para estarmos preparados no momento de nossa atuação enquanto professores. Por tal razão, contemplamos, como base teórica, o referencial da corporeidade para o entendimento do corpo-sujeito do aluno em sala de aula.

\section{Recepción: 05 Mayo 2020 | Aprobación: 09 Septiembre 2020| Publicación: 30 Septiembre 2020}


Defendemos, neste trabalho, que a corporeidade deve ser trabalhada desde a infância, para isso, os professores precisam ter a concepção de corpo/corporeidade, visto que nossa área de conhecimento busca contribuir para que essa percepção de corpo possa ser vista em sua totalidade e não como soma de partes separadas.

Diante desse quadro teórico, é imprescindível compreender como os futuros professores percebem o corpo do aluno nas aulas de Educação Física. Entretanto, é necessária uma preparação para atuar com este público de maneira que percebamos o todo, principalmente ao trabalhar o corpo/corporeidade no momento das aulas.

A partir de tais aspectos e da linha teórica deste estudo, formulamos os seguintes problemas: Como os concluintes de cursos de licenciatura em Educação Física percebem o corpo/corporeidade do aluno? O entendimento de corpo estaria ainda associado, tão somente, à visão biológica?

Em face dos problemas de estudo, o objetivo do trabalho consiste em analisar o discurso sobre o entendimento do fenômeno corpo/corporeidade junto aos alunos concluintes de cursos de licenciatura em Educação Física. Para tanto, são traçados os objetivos específicos: (a) identificar se há ainda uma concepção dualista de corpo/mente nos discursos dos alunos concluintes de cursos de licenciatura em Educação Física; e (b) reconhecer pontos de convergência e ou de divergência entre os discursos de alunos concluintes de cursos de licenciatura em Educação Física.

\section{Material e MÉtodos}

\section{Tipo de pesquisa}

Consideramos, inicialmente, pesquisa como "[...] um modo estruturado de solucionar problemas" (Th omas, Nelson \& Silverman, 2012, p. 37). Com base neste entendimento, a presente pesquisa foi norteada pelo paradigma fenomenológico-hermenêutico, que considera, entre outras características, a concepção existencial de Homem, uma dimensão interpretativa do fenômeno e o interesse dialógico e de comunicação (Chaves-Gamboa \& Sánchez Gamboa, 2009), já que tem por escopo compreender, por meio do discurso, o que alunos concluintes em cursos de Educação Física entendem sobre o fenômeno corpo/corporeidade.

Como bem afirma Triviños (2011): "A fenomenologia é o estudo das essências, e todos os problemas, segundo ela, tornam a definir essências: a essência da percepção, a essência da consciência, por exemplo" (p. 43, grifo do autor).

No que tange ao tipo de pesquisa, optamos por uma abordagem qualitativa, de cunho descritivo. Como afirma Zanella (2013), a abordagem qualitativa se preocupa com o processo da pesquisa “[...] e não com os resultados e produtos. A preocupação está em conhecer Hernández Sampieri como determinado fenômeno manifesta-se" (p. 100), ou, como esclarecem , Fernández Collado e Baptista Lucio (2010), "[...] seu enfoque é compreender e aprofundar os fenômenos, explorando-os desde a perspectiva dos participantes em um ambiente natural e em relação com o seu contexto" (p. 364, tradução nossa).

A nossa compreensão, nesta pesquisa, é de que “[...] o corpo não é apenas um objeto estático, passível de ser estudado através de suas partes. O corpo humano não está imóvel. Ele se movimenta e é o meio expressivo do ser do homem nas suas possibilidades" (Moreira, 1995, p. 51). E é por isso que concordamos com Nóbrega (2010): "O corpo não é coisa, nem ideia, o corpo é movimento, gesto, linguagem, sensibilidade, desejo, historicidade e expressão criadora” (p. 47).

\section{Coleta de dados}

A pesquisa está centrada em campi universitários localizados na região do Triângulo Mineiro - Minas Gerais, junto a duas licenciaturas (Curso A e Curso B) em Educação Física. 
Nossos participantes são caracterizados por alunos concluintes e que atendem aos seguintes critérios de inclusão:

a) Estar concluindo o curso no ano 2018;

b) Ter disponibilidade em responder duas perguntas geradoras;

c) Concordar em participar da pesquisa assinando o Termo de Consentimento Livre e Esclarecido (TCLE).

A coleta de dados foi realizada em dois dias. No primeiro dia (01/11/2018), estivemos no Curso A. No segundo dia (21/11/2018), coletamos os dados no Curso B. Ambos são oferecidos no período noturno. Cabe aqui um registro: as perguntas foram realizadas e respondidas em sala de aula. As folhas foram entregues a cada aluno e foram respondidas de maneira individual.

\section{Participantes da pesquisa}

A Figura 1 sintetiza o total e o sexo dos participantes, que são alunos concluintes da Licenciatura em Educação Física dos Cursos A e B.

Figura 1. Total de participantes da pesquisa.

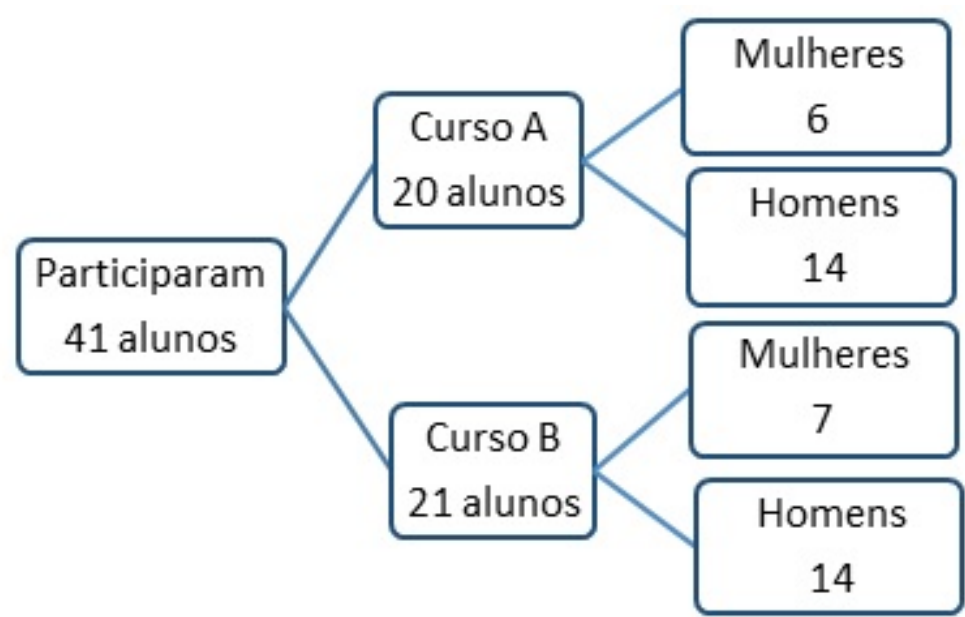

Fonte: autores da pesquisa.

$\mathrm{Na}$ Figura 1 podemos observar que participaram da pesquisa 41 concluintes de cursos de Licenciatura em Educação Física: 20 alunos pertencem ao Curso A; e 21 discentes estão vinculados ao curso B. Deste total, temos 13 mulheres e 28 homens, com idades entre 19 e 39 anos. Cabe recordar que estes cursos são oferecidos por Instituições de Ensino Superior (IES) localizadas na Região do Triângulo Mineiro, no Estado de Minas Gerais.

\section{Aspectos éticos}

Este trabalho seguiu algumas recomendações éticas referentes à pesquisa envolvendo seres humanos, a saber: vinculou-se a um projeto (CAAE: 50087115.6.0000.5154) que foi aprovado pelo Comitê de Ética em Pesquisa (CEP) da UFTM: parecer número 1.343.986 (Anexo A); utilizou um TCLE; e manteve o anonimato dos participantes da pesquisa e de suas respectivas instituições. 


\section{Instrumento de pesquisa}

O instrumento utilizado foi a entrevista com questões abertas, que reuniu duas perguntas geradoras:

1. O que é corpo para você?; $\mathrm{e}$

2. Como você exercita sua ação profissional junto ao aluno no desenvolvimento dos conteúdos aprendidos no Curso de Graduação?

Como recomenda Heinemann (2008), estas perguntas foram formuladas de forma simples, sendo breves e compreensíveis.

No contato com os participantes da pesquisa, foram apresentadas as seguintes instruções: 1) os participantes não serão identificados; 2) apresentou-se o sentido da pesquisa, solicitando que as respostas devem conter o maior número de informações possíveis, não havendo respostas certas ou erradas, deixando o tempo necessário para os participantes pensarem na elaboração das respostas; 3) entregou-se o TCLE para ser preenchido e assinado pelo participante; 4) Assim, foi disposta a primeira pergunta a ser respondida e, só após essa resposta, foi apresentada a segunda pergunta. Todo esse processo foi realizado mediante a disponibilização de folhas impressas para os participantes.

\section{Técnica de análise}

A análise realizada foi embasada no referencial contido no artigo Análise de conteúdo: técnica de elaboração e análise de unidades de significado (Moreira, Simões \& Porto, 2005), que busca identificar, nas respostas dos sujeitos participantes, os significados que estes elaboram para a vivência de um determinado fenômeno. Em nosso caso, a proposta se dirige aos discursos dos alunos concluintes dos cursos de licenciatura em Educação Física.

A referida técnica compreende três momentos de abordagem, que podem ser encontrados no discurso do sujeito:

1. Relato Ingênuo;

2. Levantamento dos Indicadores; e

3. Análise de Unidades de Significado.

No Relato Ingênuo o pesquisador procura garimpar os sentidos que os fenômenos têm para os sujeitos pesquisados através de: analisar o entendimento que os mesmos têm sobre as perguntas feitas, deixando claras as suas opiniões sobre o assunto; compreender que valores podem estar presentes nas respostas; identificar o sentido da resposta com o pano de fundo da formação profissional, neste caso (Moreira, Simões \& Porto, 2005).

No momento do Levantamento dos Indicadores são selecionadas as unidades que mais chamaram a atenção do pesquisador. Importante deixar claro que nesta abordagem de pesquisa há o entendimento de que o pesquisador não é algo ou alguém neutro na pesquisa, ele tem o compromisso de rigorosidade, de radicalidade e de contextualização sobre o fenômeno que pesquisa (Moreira, Simões \& Porto, 2005).

De posse dos indicadores, há a seleção e/ou composição das Unidades de Significado, as quais representam a base de análise e reflexão que o pesquisador irá elaborar para a construção dos resultados da pesquisa. Essas Unidades de Significado são produzidas pelas interpretações do pesquisador na busca de entender os significados dos pensamentos dos sujeitos da pesquisa, quer no sentido individual quanto coletivo do grupo respondente (Moreira, Simões \& Porto, 2005). 


\section{Resultados}

Esta seção do estudo descreve informações referentes à coleta dos dados no que tange aos participantes da pesquisa.

\section{Análise ideográfica dos cursos A e B}

Buscamos, junto à análise ideográfica de Moreira, Simões e Porto (2005), mostrar “(...) as idéias dos sujeitos individualmente (...)" (p. 110) por meio de um levantamento dos indicadores, que foi realizado com base nas respostas dos concluintes dos Cursos de Licenciatura em Educação Física A e B. O Quadro 1 descreve estes indicadores.

Quadro 1 - Indicadores referentes à Questão 1: "O que é corpo/corporeidade para você?”

\begin{tabular}{|c|c|}
\hline \multicolumn{2}{|r|}{ CURSO A } \\
\hline $\begin{array}{l}\text { PARTICIPAN } \\
\text { TES DA } \\
\text { PESQUISA }\end{array}$ & INDICADORES \\
\hline 01 & Objeto que realiza movimentos (na EF). \\
\hline 02 & $\begin{array}{l}\text { E o que proporciona as sensações, os desejos, as emoções. } \\
\text { Conjunto de músculos, ossos, articulações possibilitando locomoção. } \\
\text { Pemite conhecimento através da inteligência para a vida. }\end{array}$ \\
\hline 03 & $\begin{array}{l}\text { Corpo é o ser humano se expressando. } \\
\text { Corpo é movimento. }\end{array}$ \\
\hline 04 & $\begin{array}{l}\text { Ferramenta que usamos para a formação de órgãos, locomoção, dotado de diferentes formas (altura, gênero, cor de } \\
\text { pele). } \\
\text { Nos corpos deficientes agir para superar doenças. }\end{array}$ \\
\hline 05 & $\begin{array}{l}\text { E um amontoado de coisas que engloba músculos, nervos, veias, artérias, órgãos. } \\
\text { Uma ama com o devido treinamento. }\end{array}$ \\
\hline 06 & Máquina perfeita dotada de força e vontade. \\
\hline 07 & $\begin{array}{l}\text { E a forma de interagir com o mundo, possibilitando expressões e descobertas. } \\
\text { Corpo possibilita a convivência através do conhecimento do outro. } \\
\text { Corpo expressa movimento, falas que possibilitam conhecimento de si e do outro. } \\
\text { Devemos garantir que o corpo esteja com saúde mental e física na busca do bem-estar e disposição. }\end{array}$ \\
\hline 08 & $\begin{array}{l}\text { Instrumento para realizar atividades práticas o que o cérebro pense. } \\
\text { Mora dia da pessoa e, para mantê-la, devemos cuidar bem dela. } \\
\text { Corpo é apenas a matéria. O importante é a alma. }\end{array}$ \\
\hline 09 & Objeto que o ser humano utiliza para diversas funções. \\
\hline 10 & E a vida em movimento. \\
\hline 11 & E estar bem, com qualidade de vida, e manter equilibrio físico e mental. \\
\hline 12 & $\begin{array}{l}\text { E o mecanismo que nos movimenta. } \\
\text { E buscar qualidade de vida e ter prazer nas práticas de atividades fisicas. }\end{array}$ \\
\hline 13 & Estrutura física de um organismo, englobando funções fisiológicas. \\
\hline 14 & $\begin{array}{l}\text { Estrutura física do indivíduo o qual possibilita o movimento. } \\
\text { Movimento pode ser voluntánio e involuntánio. }\end{array}$ \\
\hline 15 & E tudo, é nossa fonte de vida. \\
\hline 16 & Instrumento que realiza atividades fisicas e mentais para alterar o meio que vive, tomando isto melhor ou pior. \\
\hline 17 & E instrumento do ser vivo quanto à saúde e o bem-estar. \\
\hline 18 & Recipiente onde se guardar tudo. E objeto da linguagem. \\
\hline 19 & E a união de corpo, mente e espíito em hamonia visando alcançar o desenvolvimento, físico e mental. \\
\hline 20 & $\begin{array}{l}\text { E conjunto de ossos, músculos e órgãos. E uma casa em construção, sempre em modificação, dependendo dos } \\
\text { estímulos, para melhorar ou para piorar. }\end{array}$ \\
\hline
\end{tabular}




\begin{tabular}{|c|c|}
\hline \multicolumn{2}{|r|}{ CURSO B } \\
\hline $\begin{array}{l}\text { PARTICIPANTES } \\
\text { DA PESQUISA }\end{array}$ & INDICADORES \\
\hline 21 & $\begin{array}{l}\text { E nossa vida, sustento, força e oporturidades. } \\
\text { O corpo precisa de cuidados para yivermps. } \\
\text { Corpo é vida. }\end{array}$ \\
\hline 22 & $\begin{array}{l}\text { E um instrumento importante que dave ser protegido. } \\
\text { Precisa de cuidados para manta-lo savdável. } \\
\text { Uma máquina fantastica que deve ser explorada }\end{array}$ \\
\hline 23 & $\begin{array}{l}\text { E tudo aquilo que pode ser trabalhado, melhor, aperfeiçoer. } \\
\text { O corpo năo pode ser transformado em uma máquina } \\
\text { Evitando ser transformado em um objeto, visto como um prêmio ou troféu. }\end{array}$ \\
\hline 24 & $\begin{array}{l}\text { O compo é um instrumento que se movimenta, vive, sente e tem realizaçôes, penas expressa } \\
\text { Corpo é live. } \\
\text { Corpo tem suas açôs de movimentos. }\end{array}$ \\
\hline 25 & $\begin{array}{l}\text { E o instrumento que expressa sentimentos es cultura } \\
\text { O conpo se relaciona comm o mundo e com a natureza. } \\
\text { O corpo é a expressâo de sentimentos através dos movimentos. }\end{array}$ \\
\hline 26 & $\begin{array}{l}\text { Meio de locomoçăo, expressåo, movimento. } \\
\text { Objeto de estudo. }\end{array}$ \\
\hline 27 & $\begin{array}{l}\text { E umasparelho muito importante. } \\
\text { E responsavel pelas transformascos do corpo através das atividades físicas e alimentares. }\end{array}$ \\
\hline 28 & E tudo que move, locomove e tem forga \\
\hline 29 & E a uniào de aspactos fisicos e psicológicos. \\
\hline 30 & $\begin{array}{l}\text { E tudo que sustenta, possibilita a movimentaçăo e o deslocamento. } \\
\text { Permite expressóes. } \\
\text { Mesmo referindo ao conpo humano, existem outras formas de corpo, como máquina, celestes etc. }\end{array}$ \\
\hline 31 & E objeto usado para a locomoçă, trabalho, no qual precisa ter descanso e cuidado para evitar doenças. \\
\hline 32 & $\begin{array}{l}\text { O corpo fala através de expressóes. } \\
\text { O corpo é valioso e precisa de cuidado. }\end{array}$ \\
\hline 33 & E a totalidade do ser humano. \\
\hline 34 & $\begin{array}{l}\text { E, somente membros. } \\
\text { Alma e a essência que possuímos. } \\
\text { É qualidade de vida } \\
\text { É praticar exercicios para exercitar os músculos. }\end{array}$ \\
\hline 35 & $\begin{array}{l}\text { O corpo transmite uma imagem de ser. } \\
\text { E sua moradis mutável. } \\
\text { Precisa ser cuidido para não ter problemas. } \\
\text { É alma e sentimento. }\end{array}$ \\
\hline 36 & E a forma de se expressar com os outros no cotidiano, mostrando o que se sente, os sentimentos, a personalidade. \\
\hline 37 & 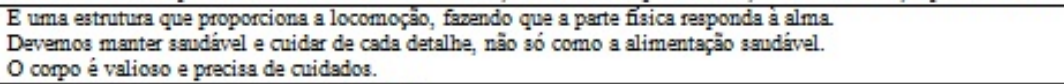 \\
\hline 38 & $\begin{array}{l}\text { E importante para tudo, para beleza e trabalho. } \\
\text { Cuidado com a saíde. }\end{array}$ \\
\hline 39 & $\begin{array}{l}\text { E algo constituido por diversos membros. } \\
\text { E uma valiosa matéria-prima } \\
\text { Devemos cuidar deste tesouro. }\end{array}$ \\
\hline 40 & E instrumento qua pode ser melhorado. \\
\hline 41 & E movimento, conhacimento de si mesmo. \\
\hline
\end{tabular}

Fonte: autores da pesquisa.

O Quadro 2 apresenta os resultados das entrevistas com os indicadores relacionados à Pergunta 2. 
Quadro 2 - Indicadores referentes à Questão 2: "Como você exercita sua ação profissional junto ao aluno no desenvolvimento dos conteúdos aprendidos no Curso de Graduação?”

\begin{tabular}{|c|c|}
\hline \multicolumn{2}{|r|}{ CURSOA } \\
\hline $\begin{array}{l}\text { PARTICIPANTES DA } \\
\text { PESQUISA }\end{array}$ & INDICADORES \\
\hline 01 & Utilização dos movimentos a partir das atividades motoras. \\
\hline 02 & $\begin{array}{l}\text { Aplicação dos conhecimentos adquiridos no curso. } \\
\text { Motivar alunos e reconhecer diferenças na relação aluno/professor. } \\
\text { Preparar para a vida em sociedade. }\end{array}$ \\
\hline 03 & Com responsabilidade e consciência. \\
\hline 04 & Passando o aprendido em sala de aula e no estágio supervisionado. \\
\hline 05 & Planejando atividades para evitar imprevistos. \\
\hline 06 & Mostrando o melhor caminho com paciência e perseverança nas aulas práticas. \\
\hline 07 & $\begin{array}{l}\text { Demonstrando os conhecimentos teónicos e práticos aprendidos na graduação. } \\
\text { Planejar aulas dentro da realidade dos alunos e da escola. } \\
\text { Valorizar os saberes dos discentes e acrescentar novos conhecimentos. }\end{array}$ \\
\hline 08 & $\begin{array}{l}\text { Atendendo às necessidades dos alunos. } \\
\text { Professor é o responsável em mostrar a importância da Educação Fisica, passar os } \\
\text { conhecimentos para aluno. }\end{array}$ \\
\hline 09 & $\begin{array}{l}\text { Desenvolver o conteúdo de forma direta, visando à melhoria da fala, do corpo e dos } \\
\text { sentimentos. }\end{array}$ \\
\hline 10 & Planejando os exercícios para os alunos. \\
\hline 11 & $\begin{array}{l}\text { Colocar o que foi aprendido com as adequações necessárias. } \\
\text { Tratando alunos com urbanidade. }\end{array}$ \\
\hline 12 & Colocando em prática o aprendido, tratando bem o aluno. \\
\hline 13 & $\begin{array}{l}\text { Colocando em prática o aprendido. } \\
\text { Considerando as questões sociais da comunidade. }\end{array}$ \\
\hline 14 & $\begin{array}{l}\text { Exercitando primeiramente alongamentos e, depois, explicando as propostas práticas a serem } \\
\text { exercitadas e os objetivo atingidos. }\end{array}$ \\
\hline 15 & $\begin{array}{l}\text { Analisando o grupo de alunos e fazendo com que o grupo fique interagindo. Motiva sempre } \\
\text { os alunos. }\end{array}$ \\
\hline 16 & $\begin{array}{l}\text { Levando os conteúdos que beneficiam os seres humanos a curto e longo prazo, nos aspectos } \\
\text { mentais e fisice. }\end{array}$ \\
\hline 17 & Aplicando a prática e a teoria, respeitando as classes social e econômica. \\
\hline 18 & $\begin{array}{l}\text { Ensinando a cultura corporal. Aplica o plano de ensino de forma a adequar-se aos alunos } \\
\text { visando melhor resultado. }\end{array}$ \\
\hline 19 & $\begin{array}{l}\text { Criando pontes entre teoria aprendida na faculdade e a realidade dos alunos. } \\
\text { Desenvolver metodologias e práticas ajustadas à realidade dos alunos. }\end{array}$ \\
\hline 20 & $\begin{array}{l}\text { Tenho o objetivo de transmitir o que foi aprendido na graduação } \\
\text { Busco o maior desenvolvimento motor equilibrio e social dos alunos. }\end{array}$ \\
\hline
\end{tabular}




\begin{tabular}{|c|c|}
\hline \multicolumn{2}{|r|}{ CURSO B } \\
\hline $\begin{array}{l}\text { PARTICIPANTES DA } \\
\text { PESQUISA }\end{array}$ & INDICADORES \\
\hline 21 & $\begin{array}{l}\text { Me exercito conversando, ensinando, aprendendo e aprimorando minha aprendizagem. } \\
\text { Aprender é tudo na nossa vida. }\end{array}$ \\
\hline 22 & $\begin{array}{l}\text { Trazendo o máximo de vivencias aos alunos. } \\
\text { Profissional deve fazer a diferença, fazendo com que o aluno absorva as oportunidades. }\end{array}$ \\
\hline 23 & $\begin{array}{l}\text { Levo como base o aprendido na faculdade. } \\
\text { No ambiente escolar a teoria aprendida na faculdade não é suficiente para desenvolver um trabalho satisfatório. }\end{array}$ \\
\hline 24 & Trabalhando com os conteúdos aprendidos em sala e usando as dicas passadas pelos professores. \\
\hline 25 & $\begin{array}{l}\text { Primeiramente respeitando o seu corpo e os seus limites de aprendizado, suas especificidades. } \\
\text { Devemos respeitar as características e especificidades dos alunos, o seu tempo e limites do seu corpo para } \\
\text { desenvolver os conteúdos. }\end{array}$ \\
\hline 26 & $\begin{array}{l}\text { Exercito com cautela, de acordo com o conhecimento que venho adquirindo e vivenciando na prática, pois o } \\
\text { aprendizado é um processo inverso, quanto mais se aprende, mais se tem a aprender. }\end{array}$ \\
\hline 27 & $\begin{array}{l}\text { Levando e aprimorando o aprendido na faculdade. } \\
\text { Buscando novos meios para aprimorar, vivenciando a realidade do meu aluno. }\end{array}$ \\
\hline 28 & $\begin{array}{l}\text { Atendendo com uma boa recepção para ganhar a confiança do aluno, assim poderei trabalhar e fazer que ele tenha } \\
\text { um bom resultado. }\end{array}$ \\
\hline 29 & $\begin{array}{l}\text { O corpo precisa estar bem junto à mente. } \\
\text { E fundamental o trabalho com o corpo, crescimento, de saúde mental e fisica, todos em harmonia. }\end{array}$ \\
\hline 30 & $\begin{array}{l}\text { Atuaria com as informações passadas pelo aluno/cliente, desta forma posso definir as metas e objetivos. } \\
\text { Informar as condições e possibilidades em curto, médio e longo prazo. }\end{array}$ \\
\hline 31 & Estudando e fazendo pesquisas para realizar um serviço de qualidade. \\
\hline 32 & $\begin{array}{l}\text { De forma mais fácil e acessivel ao aluno, trabalhando sem esquecer que devemos respeitar os limites de cada } \\
\text { aluno. }\end{array}$ \\
\hline 33 & $\begin{array}{l}\text { Aprimoro os conhecimentos aprendidos na faculdade e busco colocar em prática além de aprender mais no } \\
\text { estágio. }\end{array}$ \\
\hline 34 & $\begin{array}{l}\text { Pretendo exercer demostrando e ensinando aos futuros alunos como pode-se ter qualidade de vida. } \\
\text { Mostrando como ter uma vida com mais disposição e vontade de aprender. }\end{array}$ \\
\hline 35 & $\begin{array}{l}\text { Colocando em prática o aprendido na teoria. } \\
\text { Tento entender as limitaçóes e demanda desse aluno/cliente para conseguir atender as expectativas. }\end{array}$ \\
\hline 36 & $\begin{array}{l}\text { Buscando informação básicas sobre o aluno, pois é através dessas informações que realizo o planejamento das } \\
\text { aulas. }\end{array}$ \\
\hline 37 & $\begin{array}{l}\text { Exercito da melhor forma possivel e me coloco no lugar do outro sempre que ensino algo, pois quero o melhor } \\
\text { para todos. }\end{array}$ \\
\hline 38 & Com educação, ética, respeito e conhecimento que o profissional precisa ter. \\
\hline 39 & $\begin{array}{l}\text { Com bastante cuidado e sempre preocupando com o hoje e o amanhã. } \\
\mathrm{E} \text { através de atenção, cuidado para evitar lesões com o cliente para ele possa confiar no meu trabalho, pois o meu } \\
\text { futuro depende de tudo isso. }\end{array}$ \\
\hline 40 & Não está exercendo a profissão, mas pretende colocar em prática. \\
\hline 41 & espeitando seus limites e fazendo que ele conheça seu corpo como um todo. \\
\hline
\end{tabular}

Fonte: autores da pesquisa.

\section{Análise nomotética dos cursos A e B}

Neste momento, apresentaremos a “(...) Análise Nomotética, onde se buscam, sem a preocupação de generalizações, os pontos de convergência e ou divergência entre as idéias dos vários participantes da pesquisa" (Moreira, Simões \& Porto, 2005, p. 110). Através desta análise pretendemos mostrar as informações contidas nas reflexões dos participantes.

$\mathrm{Na}$ análise das respostas da pergunta "O que é corpo/corporeidade para você?" foram identificadas 12 Unidades de Significado (US), como pode ser observado na Tabela 1. 
Tabela 1 - Unidades de significado dos Cursos A e B referentes à questão 1: "O que é corpo/corporeidade para você?"

\begin{tabular}{|c|c|c|c|c|c|c|c|c|c|c|c|c|c|c|c|c|c|c|c|c|c|c|c|c|c|c|c|c|c|c|c|c|c|c|c|c|c|}
\hline \multirow[t]{2}{*}{$\begin{array}{c}\text { UNIDADES } \\
\text { DE SIGNIFICADO }\end{array}$} & \multicolumn{35}{|c|}{$\begin{array}{l}\text { Participantes da pesquisa } \\
\text { (Cursos A e B) }\end{array}$} & \multicolumn{2}{|c|}{ TOTAL } \\
\hline & A & & 23 & $4:$ & 56 & 7 & 89 & 10 & 11 & \begin{tabular}{l|l}
12 & 1 \\
\end{tabular} & 13 : & 14.1 & $\begin{array}{ll}15 & 16 \\
\end{array}$ & \begin{tabular}{|l|l}
6 & \\
\end{tabular} & 18 & 9. 20 & & 21 & \begin{tabular}{|l|l|}
22 & 23 \\
\end{tabular} & ${ }_{23} 24$ & 25 & 26 & 27 & 28 & 29 & \begin{tabular}{l|l}
30 & 31 \\
\end{tabular} & $\begin{array}{ll}31 & 32 \\
\end{array}$ & 33 & 34 & 35 & 36 & 37 & \begin{tabular}{l|l}
38 & 35 \\
\end{tabular} & 9. 40 & $\begin{array}{ll}0 & 41 \\
\end{array}$ & $\begin{array}{c}\text { Valor } \\
\text { absoluto }\end{array}$ & $\begin{array}{c}\text { Valor } \\
\text { relativo }\end{array}$ \\
\hline $\begin{array}{l}\text { 1) Míquina/ / Objeto/ / } \\
\text { Apareloho / Recipiente/ } \\
\text { Ferramenta } \\
\text { Instrumento }\end{array}$ & & $\mathrm{x}$ & & $\mathrm{x}$ & $\mathrm{x}$ & & $\mathrm{x}$ & & & $\mathrm{x}$ & $\mathrm{x}$ & $\mathrm{x}$ & $\mathrm{x}$ & $\mathrm{x}$ & $\mathrm{x}$ & & & & $\mathrm{x}$ & $\mathrm{x}$ & $x$ & $\mathrm{x}$ & $\mathbf{x}$ & & & $\mathrm{x} x$ & $\mathrm{x}$ & & & & & $\mathbf{x}$ & & $\mathrm{x}$ & & 20 & $48,78 \%$ \\
\hline $\begin{array}{l}\text { 2) Movimento/ } \\
\text { Locomocáo }\end{array}$ & & & $\mathrm{x} x$ & $\mathrm{x}$ & & $\mathrm{x}$ & & $\mathrm{x}$ & & & & $\mathrm{x}$ & & & & & & & & $\mathrm{x}$ & $\mathrm{x}$ & $\mathrm{x}$ & & $\mathrm{x}$ & & $\mathrm{x}$ & & & & & & $\mathrm{x}$ & & & $\mathrm{x}$ & 13 & $31,70 \%$ \\
\hline vida/ Saúde & & & & & & $\mathrm{x}$ & & & $\mathrm{x}$ & $\mathrm{x}$ & & 2 & $\mathrm{x}$ & $\mathrm{x}$ & & & & $\mathrm{x}$ & & & & & & & & & & & $\mathrm{x}$ & & & $\mathbf{x}$ & & & & 8 & $19,51 \%$ \\
\hline 4) Expr & & & $\mathrm{x}$ & & & $\mathbf{x}$ & & & & & & & & & & & & & & & $\mathrm{x}$ & $\mathrm{x}$ & & & & $\mathrm{x}$ & $\mathrm{x}$ & & & & $\mathrm{x}$ & & & & & 7 & $17,07 \%$ \\
\hline Alma e a ess & c & & & & & & $\mathbf{x}$ & & & & & & & & & & $\mathrm{c}$ & & & & & & & & & $\mathrm{x}$ & & & $x$ & $\mathrm{x}$ & & $\mathrm{x}$ & & & & 5 & $12,19 \%$ \\
\hline ๑E Etudo/Totalidade & R & & & & & & & & & & & & & & & & $\mathrm{V}_{\mathrm{R}}$ & & $\mathrm{x}$ & $\mathrm{x}$ & & & & & & & $\mathrm{x}$ & $\mathrm{x}$ & & & & $\mathbf{x}$ & & & & 4 & $9,75 \%$ \\
\hline $\begin{array}{l}\text { 7) Conjunto de } \\
\text { músculos, ossos, } \\
\text { articulaçes }\end{array}$ & $\begin{array}{ll}\mathrm{s} \\
\mathrm{o}\end{array}$ & $x$ & $\mathrm{x}$ & & $\mathrm{x}$ & & & & & & & & & & & $\mathrm{x}$ & $\begin{array}{ll}\mathrm{s} \\
\mathrm{x}\end{array}$ & & & & & & & & & & & & $\mathrm{x}$ & & & & $\mathrm{x}$ & & & 4 & $9,75 \%$ \\
\hline $\begin{array}{l}\text { artuculaçoes } \\
\text { 8) Uniâo de corpo, } \\
\text { mente e espipito/ } \\
\text { Equilibrio fisico e } \\
\text { mental }\end{array}$ & A & & & & & & & & $\mathrm{x}$ & & & & & & & $\mathrm{x}$ & B & & & & & & & & $\mathrm{x}$ & & & & & & & & & & & 3 & $7,31 \%$ \\
\hline $\mathrm{Ca}_{2}$ & & & & & & & $\mathbf{x}$ & & & & & & & & & & & & & & & & & & & $\mathrm{x}$ & & & & $\mathrm{x}$ & & & & & & 3 & $7,31 \%$ \\
\hline 10) $\mathrm{Cul}$ & & & & & & & & & & & & & & & & & & & & & $\mathrm{x}$ & & & & & & & & & & & & & & & 1 & $2,43 \%$ \\
\hline & & & & & & & & & & & & & & & & & & & & $\mathrm{x}$ & & & & & & & & & & & & & & & & 1 & $2,43 \%$ \\
\hline 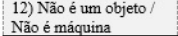 & & & & & & & & & & & & & & & & & & & $\mathrm{x}$ & $\mathrm{x}$ & & & & & & & & & & & & & & & & 1 & $2,43 \%$ \\
\hline
\end{tabular}

Já na análise das respostas da pergunta "Como você exercita sua ação profissional junto ao aluno no desenvolvimento dos conteúdos aprendidos no curso de graduação?” identificamos nove US na Tabela 2.

Tabela 2 - Unidades de significado dos Cursos A e B referentes à questão 2: "Como você exercita sua ação profissional junto ao aluno no desenvolvimento dos conteúdos aprendidos no Curso de Graduação?”

\begin{tabular}{|c|c|c|c|c|c|c|c|c|c|c|c|c|c|c|c|c|c|c|c|c|c|c|c|c|c|c|c|c|c|c|c|c|c|c|c|c|c|c|c|c|c|c|c|c|c|}
\hline \multirow{2}{*}{$\begin{array}{c}\text { UNIDADES } \\
\text { DE } \\
\text { SIGNIFICADO }\end{array}$} & \multicolumn{43}{|c|}{$\begin{array}{c}\text { Participantes da pesquisa } \\
\text { (Cursos A e B) }\end{array}$} & \multicolumn{2}{|c|}{ TOTAL } \\
\hline & A & 1 & 2 & 3 & 4 & 5 & 6 & 7 & 8 & 9 & 10 & 11 & 12 & 13 & 14 & 15 & 16 & 17 & 18 & 19 & 20 & B & 21 & 22 & 23 & 24 & 25 & 26 & 27 & 28 & 29 & 30 & 31 & 32 & 33 & 34 & 35 & 36 & 37 & 38 & 39 & 40 & 41 & \begin{tabular}{c|}
$\begin{array}{c}\text { Valor } \\
\text { absoluto }\end{array}$ \\
\end{tabular} & $\begin{array}{l}\text { Valor } \\
\text { relativo }\end{array}$ \\
\hline $\begin{array}{l}\text { 1) Planejando as } \\
\text { atividades/ } \\
\text { Conteudo }\end{array}$ & & & & & & $\mathrm{x}$ & & $\mathrm{x}$ & $\mathrm{x}$ & & $\mathrm{x}$ & & & & $\mathrm{x}$ & & $\mathrm{x}$ & $\mathrm{x}$ & $\mathrm{x}$ & $\mathrm{x}$ & & & $\mathrm{x}$ & & & & $\mathrm{x}$ & & & & & $\mathrm{x}$ & & $\mathrm{x}$ & & & & $\mathrm{x}$ & & $\mathrm{x}$ & & & $\mathrm{x}$ & 16 & 39,02 \\
\hline $\begin{array}{l}\text { 2) Explicando / } \\
\text { Demostrando o } \\
\text { conhecimento } \\
\text { adquirido }\end{array}$ & & & $\mathbf{x}$ & & $\mathrm{x}$ & & & & $x$ & $\mathrm{x}$ & & $\mathrm{x}$ & $\mathrm{x}$ & $\mathrm{x}$ & & & & & & $\mathrm{x}$ & $\mathrm{x}$ & & & & $x$ & $\mathrm{x}$ & & $\mathrm{x}$ & $\mathrm{x}$ & & & & & & & & $\mathrm{x}$ & & & & & & & 14 & 34,14 \\
\hline $\begin{array}{l}\text { 3) Motivacãa / } \\
\text { Reconhecimento } \\
\text { das } \\
\text { individualidades }\end{array}$ & $\begin{array}{l}\mathrm{C} \\
\mathrm{U}\end{array}$ & & $\mathrm{x}$ & & & & & $\mathrm{x}$ & $\mathbf{x}$ & & & & & & & $\begin{array}{ll} \\
\end{array}$ & & & & & & $\mathrm{U}$ & & & & & $\mathrm{x}$ & & & $\mathrm{x}$ & & & & & & & $\mathrm{x}$ & & & & & & $\mathrm{x}$ & 8 & $19,51 \%$ \\
\hline 4) Confiança & $\mathbf{R}$ & & & $\mathrm{x}$ & & & & & & & & & & & & & & & & & & R & $\mathrm{x}$ & $\mathrm{x}$ & & & & & & $\mathrm{x}$ & & & & & & $\mathrm{x}$ & & & $\mathrm{x}$ & $\mathrm{x}$ & $\mathrm{x}$ & & & 8 & $19,51 \%$ \\
\hline 5) Especialização & o & & & & & & & $\mathrm{x}$ & & & & & & & & & & & & & & 0 & & & & & & $\mathrm{x}$ & $\mathrm{x}$ & & & & $\mathrm{x}$ & & $\mathrm{x}$ & & & & & & & & & 5 & $12,19 \%$ \\
\hline $\begin{array}{l}\text { 6) Trabalhar } 0 \\
\text { corpo como } \\
\text { totalidade }\end{array}$ & A & & & & & & & & & $\mathrm{x}$ & & & & & & & & & $\mathrm{x}$ & & & B & & & & & $\mathrm{x}$ & & & & $\mathrm{x}$ & & & & & & & & & & & & $\mathrm{x}$ & 5 & $12,19 \%$ \\
\hline $\begin{array}{l}\text { 7) Utiliza os } \\
\text { movimentos }\end{array}$ & & $\mathbf{x}$ & & & & & & & & & & & & & & & & & $\mathrm{x}$ & & $x$ & & & & & & $\mathrm{x}$ & & & & & & & & & & & & & & & & & 4 & $9,75 \%$ \\
\hline $\begin{array}{l}\text { 8) Não fez estágio / } \\
\text { Não exerce }\end{array}$ & & & & & & & & & & & & & & & & & & & & & & & & & & & & & & & & $x$ & & & & $\mathrm{x}$ & & & & & & $\mathrm{x}$ & & 3 & $7,31 \%$ \\
\hline $\begin{array}{l}\text { 9) A A teoria } \\
\text { aprendida na } \\
\text { faculdade não é } \\
\text { suficiente }\end{array}$ & & & & & & & & & & & & & & & & & & & & & & & & & $x$ & & & & & & & & & & & & & & & & & & & 1 & $2,43 \%$ \\
\hline
\end{tabular}

Fonte: autores da pesquisa.

\section{Discussão}

Decidimos realizar três análises das unidades de significado: na primeira, analisamos todas as respostas na horizontal incluindo todos os participantes; na segunda, temos uma análise na vertical, onde estão presentes todos os participantes, porém, discutimos apenas os dados que apresentaram informações relevantes a serem discutidas; na terceira análise, comparamos as respostas dos cursos A e B de cada pergunta.

$\mathrm{Na}$ análise ideográfica dos indicadores da Pergunta 1 ("O que é corpo/corporeidade para você??) tivemos doze participantes que demostraram uma preocupação com o cuidado com o corpo, sendo eles: participantes $05,07,08,11,21,22,31,32,35,37,38$ e 39 . A respeito dessas respostas, Gonçalves-Silva, Souza, Simões e Moreira (2016) advertem:

Quando se tem a visão de que o corpo é só a forma física e que este deve ser cuidado e tratado enquanto objeto o qual se possui, reduzimos a possibilidade de entender o sujeito de forma integral. Logo, em relação a uma interpretação da Educação Física 
como educação do físico, podemos inferir que não se trata de uma educação que compreenda o sujeito em sua totalidade, mas sim fragmentado e, nesse sujeito, as partes devem ser trabalhadas, separadamente, com o fim em si mesmo (p. 192).

Percebemos que a ideia de "cuidado" com corpo, mencionada pelos participantes, está ligada a um objeto que precisa estar constantemente em reparo. E é o que os autores chamam atenção, mas essa visão pode ser mudada com o tempo se esse futuro profissional começar a usar seu conhecimento sobre corporeidade adquirido na universidade, assim, seu olhar de corpo poderá mudar.

Entre estes doze concluintes, o participante 05 nos chamou muito atenção, por ter dito que o corpo "em alguns lugares é considerado um templo onde você deve se cuidar, pode ser considerado como uma arma com o devido treinamento."

Sua resposta demostra ambivalência, provavelmente advinda de uma formação religiosa (templo) para a qual o corpo é um revestimento para a alma e, ao mesmo tempo, uma visão utilitarista de conquista através de treinamento.

Silva, Hochamnn e Piccinini (2015) mostram que nossa percepção de corpo / corporeidade não pode estar restrita apenas ao "(...) físico, mas dos nossos valores, do mental e intelectual. A corporeidade é o diálogo entre corpo, mente espiritualidade e a sua relação com o mundo" (p. 97).

No que concerne à análise nomotética da Pergunta 1, identificamos um total de 12 US; destas, destacamos a primeira, a segunda e a oitava unidade. Na primeira encontramos quase $50 \%$ das respostas com um olhar mais mecânico "máquina", totalizando a maior convergência com 20 participantes, indo ao encontro da fala de Moreira (2012), quando diz que o paradigma do modelo cartesiano ainda está presente nos argumentos.

Em outra pesquisa, Moreira, Chaves e Simões (2017) advertem: ao “(...) considerar o corpo como máquina a ser melhorada em seu rendimento para atingir a perfeição, porque nesta trilha já partimos do princípio que o corpo humano é imperfeito, justificando todo tipo de manipulação e de invasão para consertá-lo" (p. 203). Encontramos uma divergência neste pensamento sobre a concepção de corpo/corporeidade, pois os graduandos do curso de Educação Física precisam “(...) colaborar para a análise e o entendimento da corporeidade no contexto da condição humana” (Moreira, Chaves \& Simões, 2017, p. 208). E os autores, em seguida, complementam:

O estudo do ser humano que se movimenta intencionalmente na direção da superação ou transcendência, através dos conhecimentos históricos da chamada Educação Física, deve estar atrelado ao entendimento da complexidade humana (p. 208).

Merleau-Ponty (2011) afirma que "a consciência do corpo e a alma são assim repelidos, o corpo volta a ser esta máquina bem limpa que a noção ambígua de comportamento falhou em fazer-nos esquecer” (p. 115).

Ainda na análise nomotética da Pergunta 1, temos uma convergência de 31,70\% das respostas presentes nas US de 13 participantes, no qual o corpo/corporeidade é "movimento / locomoção".

Com apenas 7,31\% (três participantes) aparece a oitava US, que apresenta respostas relacionadas à "União de corpo, mente e espírito / Equilíbrio físico e mental”. Nesta perspectiva, esta US parece caminhar no sentido do entendimento dos pressupostos da corporeidade. No entanto, aqui vale uma observação: na verdade, o sentido de corporeidade não é necessariamente a junção de equilíbrio "físico e mental", nem mesmo "união de corpo, mente e espírito". No primeiro caso, em que aparece a conjunção e, significa um mais outro. No segundo caso corporeidade não é união de várias coisas, e sim uma unidade indissociável.

Nesta segunda análise nomotética das US, no sentido vertical, conseguimos perceber que os participantes 23, 25, 30 e 37 demostraram uma percepção de corpo/corporeidade, de uma maneira que chamou a nossa atenção.

O participante 23, ao mesmo tempo que menciona que o corpo/corporeidade "não é um objeto / não é máquina", também diz que ele é "É tudo / Totalidade".

Seguindo a análise, temos os participantes 25,30 e 37, os quais demostraram ter uma divergência na percepção de corpo/corporeidade em suas respostas, ao explicitar o corpo como máquina. A título de 
ilustração, observe-se o participante 25 , que, além de mencionar o corpo como máquina, afirma que corpo é "movimento / locomoção e expressão", e, por fim, "cultura". Apresentando a mesma divergência, temos os participantes 30 e 37, que, além de caracterizarem corpo como máquina, falam que corpo é "movimento / locomoção", "alma / celestial, alma e a essência", "moradia mutável / casa em construção", "expressão" e "é tudo / totalidade".

Na última análise nomotética das US da Pergunta 1, foi possível comparar o entendimento de corpo/ corporeidade dos participantes em relação às respostas dos cursos A e B, como pode ser visto, as US de número “3, 4, 5 e 6" são mais assinaladas por ambos os cursos.

Notamos que a US número 3 (Fonte de vida / Saúde / Bem-estar) foi apontada por cinco participantes do curso A e, por apenas três no curso B.

A US número 4 (Expressão) foi apresentada duas vezes no Curso A, em contrapartida, tivemos cinco respostas no Curso $B$.

A US 5 (Alma / Celestial Alma e a Essência) foi mencionada por apenas um participante do Curso A, por outro lado, foi apresentada por quatro participantes do Curso B. E, por fim, temos algo que nos impressionou no Curso B, que foi a US número 6 (É tudo / Totalidade), que computou quatro participantes e, no Curso A, foi ausente. Com isso, é possível notar que os concluintes do Curso B têm um entendimento de corpo/ corporeidade mais ampliado em relação aos alunos do Curso A.

$\mathrm{Na}$ análise ideográfica dos indicadores da Pergunta 2 ("Como você exercita sua ação profissional junto ao aluno no desenvolvimento dos conteúdos aprendidos no Curso de Graduação?”) tivemos 12 participantes que mencionaram que utilizam o aprendido na faculdade, sendo eles: participantes 02, 04, 07,11, 12 19, 20, 23, 24, 27, 33 e 35, pois foram as respostas mais frequentes, por eles terem colocado que "utilizam o aprendido em sala de aula".

Sendo assim, esses nove participantes poderiam buscar uma especialização, ao invés de reproduzir apenas o aprendido, pois, estarão em um ambiente diferente da graduação, no qual atuarão como professor, momento em que devem trabalhar tanto o coletivo quanto a individualidade de cada aluno.

Notamos que os participantes 09, 29 e 41 têm o pensamento voltado para trabalhar o corpo em sua totalidade. Nesta direção, Santin (2011) nos contempla com a seguinte reflexão:

A compreensão da corporeidade por meio de conceitos e definições de manuais precisa ser completada pela observação das imagens corpo que se constroem no imaginário social que, na última instancia, são as determinam a vivência corporal (p. 53).

E, por fim, tivemos, dois participantes com os pensamentos semelhantes: o participante 21, que exercita o aprendido "(...) conversando, ensinando, aprendendo e fortalecendo o aprendizagem, o aprender e tudo na nossa vida"; e o participante 22 menciona que a forma de exercer a docência é "trazendo o máximo de vivencias aos alunos" e que o "profissional deve fazer a diferença fazendo com que o aluno absorva as oportunidades".

No que concerne à análise nomotética da Pergunta 2, identificamos nove US e destacamos: a primeira, terceira e sexta unidades. Notamos que a primeira US - "Planejando as atividades / conteúdo" - mostra que 39,02\% dos concluintes demostraram ter a preocupação com o planejamento das aulas. A terceira US - "Motivação / Reconhecimento das individualidades" - apresenta 19,51\% dos participantes da pesquisa. Este grupo, sem dúvida, demostra a preocupação em motivar seu aluno durante as aulas. Por último, a sexta US - "Trabalhar o corpo como totalidade" - totaliza 12,19\% das respostas. Compreender o corpo em sua totalidade é uma maneira de pensar que se aproxima do referencial da Corporeidade.

Em contrapartida, tivemos 14 participantes que pensam unicamente em ensinar somente o que foi aprendido durante o percurso da graduação. Por outro lado, obtivemos uma interessante resposta do participante 23, que afirmou: "A teoria aprendida na faculdade não é suficiente".

A análise nomotética das US da Pergunta 2 - cujo objetivo foi comparar os Cursos A e B - revela uma maior frequência das US de número "2", "5" e "6". Notamos que a US de número 2 - "Explicando / Demostrando o conhecimento adquirido" - apresenta um valor absoluto de 14 participantes (nove do Curso 
A e cinco do Curso B). A US número 5 - "Especialização" - teve o valor absoluto de cinco participantes (um do Curso A e quatro do Curso B). Pensando na atuação com o "corpo", tivemos a US de número 6 "Trabalhar o corpo como totalidade" - que apresentou um valor absoluto de cinco participantes (dois no Curso A e três no Curso B).

\section{CONSIDERAÇÕES FINAIS}

A presente pesquisa evidenciou que a percepção de corpo/corporeidade que os concluintes dos cursos de licenciatura em Educação Física é um pensamento presente no modelo cartesiano, uma visão de corpo voltada para a parte biológica, ignorando que somos seres corpóreos e que o corpo deve ser trabalhado como um todo, ao contrário de uma máquina.

Em face dos problemas estabelecidos e dos objetivos do estudo, podemos mencionar que conseguimos confirmá-los, uma vez que constatamos que os participantes da pesquisa manifestaram uma percepção de corpo relacionada à máquina, objeto pelo qual se pode modelar, ajustar e/ou aperfeiçoar, sendo este entendimento visível e manifesto no discurso dos concluintes dos cursos de Licenciatura A e B.

Em termos de aportações didáticas deste trabalho à Educação Física, consideramos que descortinar a compreensão de corpo/corporeidade, oriunda de licenciandos concluintes em cursos da área, pode ser um passo para apontar uma necessidade de melhorar a formação inicial neste aspecto e, por consequência, uma melhor qualidade na seleção de conteúdos e planejamento curricular na prática pedagógica da Educação Física no contexto escolar.

Por último, recomendamos que futuras pesquisas sobre a concepção de corpo/corporeidade presente no discurso de estudantes de Educação Física sejam realizadas. Um interessante estudo seria analisar qual o entendimento de corpo/corporeidade por alunos ingressantes em Cursos de Educação Física.

\section{REFERÊNCIAS}

Chaves-Gamboa, M., \& Sánchez Gamboa, S. (2009). Pesquisa na educação física: epistemologias, escola e formação profissional. Maceió: Edufal.

Gonçalves-Silva, L. L., Souza, M. C. R. F., Simões, R., \& Moreira, W. W. (2016). Reflexões sobre corporeidade no contexto da educação integral. Educação em Revista, 32(1), 185-209. Recuperado de http://www.scielo.br/sciel o.php?pid=S0102-46982016000100185\&script $=$ sci_abstract\&tlng=pt

Heinemann, K. (2008). Introducción a la metodología de la investigación empirica en las ciencias del deporte. (2a ed rev. e ampl.). Badalona: Paidotribo.

Hernández Sampieri, R., Fernández Collado, C., \& Baptista Lucio, M. del P. (2010). Metodología de la investigación. (5 $5^{\mathrm{a}}$ ed). Colombia: McGrawHill.

Merleau-Ponty, M. (2011). Fenomenologia da percepção. São Paulo: WMF Martins Fontes.

Moreira, W. W. (1995). Educação física escolar: uma abordagem fenomenológica. (3a ed). Campinas: Editora da Unicamp.

Moreira, W. W. (2012) Formação profissional em ciência do esporte: homo sportivus e humanismo. In: Bento, J. O., \& Moreira, W. W. Homo Sportivus: o humano no homem (pp. 113-180). Belo Horizonte: Instituto Casa da Educação Física.

Moreira, W. W., Chaves, A. D., \& Simões, R. M. R. (2017). Corporeidade: uma base epistemológicas para a ação da educação física. Motrivivência, 29( 50), 202-212. Recuperado de https://periodicos.ufsc.br/index.php/motrivi vencia/article/view/2175-8042.2017v29n50p202/34007

Moreira, W. W., Simões, R., \& Porto, E. (2005). Análise de conteúdo: técnica de elaboração e análise de unidades de significado. Revista Brasileira de Ciência e Movimento, 13(4), 107-114.

Nóbrega, T. P. da (2010). Uma fenomenologia do corpo. São Paulo: Livraria da Física. 
Santin, S. (2011). Perspectivas na visão da corporeidade. In: Moreira, W. W. (org.). Educação física \& esportes: perspectivas para o século XXI (pp. 51-69). (17 ed). Campinas: Papirus.

Silva, A. C. de M., Hochamnn, A. S., \& Piccinini, L. (2015). Corporeidade: um corpo-próprio nas aulas de educação física. Revista Cientifica Emersão, 1(1), 95-106.

Thomas, J. R., Nelson, J. K., \& Silverman, S. J. (2012). Métodos de pesquisa em atividade física. (6a ed). Porto Alegre: Artmed.

Triviños, A. N. S. (2011). Introdução à pesquisa em ciências sociais: a pesquisa qualitativa em educação. O positivismo, a fenomenologia, o marxismo. São Paulo: Atlas.

Zanella, L. C. H. (2013). Metodologia de pesquisa. (2 ${ }^{\text {a }}$ ed. reimp.). Florianópolis: UFSC, Departamento de Ciências da Administração. 